\title{
Musical Instruments for Novices: Comparing NIME, HCI and Crowdfunding Approaches
}

\author{
Andrew McPherson, Fabio Morreale and Jacob Harrison
}

\begin{abstract}
Designing musical instruments to make performance accessible to novice musicians is a goal which long predates digital technology. However, just in the space of the past 6 years, dozens of instrument designs have been introduced in various academic venues and in commercial crowdfunding campaigns. In this paper, we draw comparisons in design, evaluation and marketing across four domains: crowdfunding campaigns on Kickstarter and Indiegogo; the New Interfaces for Musical Expression (NIME) conference; conferences in human-computer interaction (HCI); and researchers creating accessible instruments for children and adults with disabilities. We observe striking differences in approach between commercial and academic projects, with less pronounced differences between each of the academic communities. The paper concludes with general reflections on the identity and purpose of instruments for novice musicians, with suggestions for future exploration.
\end{abstract}

\section{Introduction}

While listening to music is a nearly universal human activity, not everyone engages in musical performance. The advent of recording and broadcast media in the 20th century reduced the barriers to music consumption, but also lessened the incentive for personal music making in the home. A survey by Nielsen Scarborough found that in 2014, 27.8 million US adults played a musical instrument, down from 29

\footnotetext{
Andrew McPherson

Centre for Digital Music, Queen Mary University of London e-mail: a.mcpherson@qmul.ac.uk

Fabio Morreale

Centre for Digital Music, Queen Mary University of London e-mail: f.morreale@qmul.ac.uk

Jacob Harrison

Centre for Digital Music, Queen Mary University of London e-mail: j.harrison@qmul.ac.uk
} 
million in $2011 .{ }^{1}$ A 2014 UK study by the $\mathrm{ABRSM}^{2}$ found that $34 \%$ of adults currently play an instrument. Though variations in study methodology make a robust estimate difficult to obtain, it is clear that instrumental performers are a minority of the overall adult population.

While electronic technology, through music distribution, has been a contributor to the decline of amateur performance, it is also frequently proposed as an enabler. Perhaps, the argument goes, the ready availability of cheap computing power could help make musical performance more accessible to novices by reducing the traditional barriers to entry of learning a musical instrument. In place of the hundreds of hours needed to achieve basic tone production on many acoustic instruments and the thousands of hours needed to reach full proficiency, a specially-designed digital musical instrument could provide an immediately engaging experience of producing music with minimal prior training. Wessel and Wright (2002) refer to this ease of use as a "low entry fee" and propose that digital musical instruments should also place "no ceiling on virtuosity".

The idea of new instruments making music accessible has historical roots far predating the digital era. The harmonica, autoharp and tin whistle were designed or marketed as being easy to play. The 19th century saw numerous patents for instrument adaptations designed to make them easier to play, often using keyboard mechanisms to reduce the underlying mechanical complexity of an instrument (Tresch and Dolan, 2013). At the dawn of the digital era, the 1981 Suzuki Omnichord was similarly designed for ease of use by novice musicians.

The past 30 years have seen an abundance of creative new approaches to instrument design for musical novices, many of which are described in later sections of this paper. Another approach, found in both academic and commercial settings since the 1980's, is the conductor system (Mathews, 1991), where a complete piece of music is embedded within the instrument and the performer is given control over highlevel features of its playback such as tempo or loudness; see Chew and McPherson (2017) for further discussion.

This paper provides a snapshot of the state of play in digital musical instrument design for novices and non-musicians. It does not aim at a comprehensive review of all such work; rather, it provides a detailed investigation of the last few years of development in four domains: commercial crowdfunding campaigns (Kickstarter and Indiegogo); the NIME conference; human-computer interaction (HCI) conferences; and the community specifically catering to individuals with physical and mental impairments. The paper examines the differences in technical, artistic and commercial approaches across these four domains and seeks to identify some of the implicit assumptions instrument developers make about musical performance. The paper concludes with thoughts on the way forward in addressing this persistently interesting topic.

\footnotetext{
${ }^{1}$ https://www.statista.com/statistics/352204/number-of-people-play-musical-instrument-usa/

2 https://gb.abrsm.org/en/making-music/4-the-statistics/
} 


\section{Crowdfunding Campaigns}

This section reviews new musical instruments released on the crowdfunding sites Kickstarter and Indiegogo. ${ }^{3}$ We searched for all completed campaigns launching new musical instruments which received at least 50,000 in funding in its local currency (dollars, pounds, euro). ${ }^{4}$ Any instrument for live musical performance was considered regardless of its form or who it was marketed to. Albums, performances, site-specific installations, audio effects and other music products were excluded. We identified 30 instruments meeting these criteria, summarised in Tables 1 and 2.

\footnotetext{
${ }^{3}$ http://kickstarter.com and http://indiegogo.com

${ }^{4}$ Approximate exchange rate as of January 2018: $\$ 1=€ 0.8=£ 0.7$. For simplicity, and because exchange rates have varied significantly over the 2012-17 period, a fixed threshold of 50k was chosen in each currency.
} 
Table 1 Musical instruments crowd-funded on Kickstarter and Indiegogo. Date indicates when the campaign finished.

Name

jamstik+ the SmartGuitar

MI Guitar by Magic Instruments

Date Raised Type

Tagline

13/04/15 \$1.3M MIDI multi- instrument controller

07/05/15 \$813k Wireless MIDI guitar controller

22/06/16 \$412k MIDI guitar controller

gTar: The First Guitar That Anybody 25/06/12 \$353k MIDI guitar controller Can Play

Oval - The First Digital HandPan $\quad 12 / 07 / 15 € 349 k$ MIDI percussion

controller

Spolum Drum - the musical

instrument of happiness

Dualo - The new musical instrument 11/05/16 €217k MIDI isomorphic

for all

Lumen: the Electro-Acoustic

Handpan

KordBot - Music Production

02/08/17 \$288k Acoustic metal drum

Assistant

dadamachines: music machines for $\quad 02 / 05 / 17 € 168 \mathrm{k}$ MIDI actuator kit

everyone!

QuNeo, 3D Multi-touch Open

Source MIDI \& USB Pad Controller

Minim: Pocket-sized Wireless

Instrument for Music Creation

Phenol Patchable Analog

Synthesizer

controller withs

15/05/16 \$182k Percussion instrument with MIDI

23/03/16 \$178k MIDI button controller

Remidi: First Wearable Instrument to 18/03/16 \$137k MIDI glove controller

Record, Play \& Perform

C.24 - The Music Keyboard for iPad 08/08/13 \$136k portable MIDI keybo

The Vo-96 Acoustic Synthesizer

13/05/13 \$120k guitar string actuator

Hyve Touch Synth: Make the future 19/04/17 \$105k Capacitive touch synth of musical expression
Strum a guitar, bow a violin, tap a piano, loop a beat - on a single instrument. An intuitive way to create music and play any sound. A portable guitar that teaches you to play, sounds like any musical instrument and connects wirelessly so you can play guitar anywhere.

Anyone who has ever yearned to play a musical instrument, the MI Guitar makes it happen in minutes.

The gTar is a fully digital guitar that enables anybody to play music quickly and easily with the help of LEDs and a docked iPhone

A new electronic musical instrument which allows you to play, learn and perform music using any sound you can imagine.

An instrument for relaxation, meditation, creativity, and happiness! Anyone can play it!

Experience the joy of creating your own music with one intuitive \& stand alone instrument. Play and compose wherever you want.

A fully self-contained electronic percussion instrument in the form of a traditional handpan.

KordBot is a MIDI controller that gives you 1000's of chords at the touch of a button, a powerful arpeggiator \& step sequencer in one!

Tap, move and bang to make sound with the world around you. Hackable \& open-source!

QuNeo is a break-through 3D pad controller for electronic musicians, digital DJs, VJs \& DIY hackers providing multi-touch control.

Expressively control your favorite music creation apps \& software. Make music anywhere with any sound, all on one instrument.

An affordable patchable analog synthesizer. Create music and sound like never before with this unique instrument.

Sensors in fingers \& palm trigger custom sounds while connected wristcontroller/hand gestures control effects with reverb, echo, etc.

The C. 24 is a two octave wireless music keyboard designed for iPad.

A fun, expressive musical instrument you can make, hack and play. Build a beautiful analog synth that responds to touch and movement 
Table 2 Musical instruments crowd-funded on Kickstarter and Indiegogo (continued). Date indicates when the campaign finished.

\begin{tabular}{|c|c|c|c|c|}
\hline Name & Date & Raised & Type & Tagline \\
\hline Mogees - Play the World & 19/03/14 & $£ 96 \mathrm{k}$ & $\begin{array}{l}\text { Contact mic with audio } \\
\text { processing }\end{array}$ & $\begin{array}{l}\text { Mogees turns the everyday objects around you into unique and powerful } \\
\text { musical instruments. Play the world! }\end{array}$ \\
\hline $\begin{array}{l}\text { Joué - The most Expressive and } \\
\text { Modular MIDI controller }\end{array}$ & $15 / 01 / 17$ & $€ 91 \mathrm{k}$ & MIDI controller & $\begin{array}{l}\text { Joué is an innovative instrument simplifying digital music playing and } \\
\text { offering a unique level of expressivity and spontaneity. }\end{array}$ \\
\hline imitone: mind to melody & $10 / 04 / 14$ & $\$ 90 \mathrm{k}$ & audio-to-MIDI software & imitone lets you play any instrument with your voice. \\
\hline $\begin{array}{l}\text { The Motion Synth: Turn Movement } \\
\text { into Music }\end{array}$ & $19 / 12 / 13$ & $\$ 75 \mathrm{k}$ & $\begin{array}{l}\text { iOS MIDI controller app } \\
\text { with phone case }\end{array}$ & $\begin{array}{l}\text { Transform your iPhone or iPod touch into an intuitive and expressive } \\
\text { motion-controlled musical instrument }\end{array}$ \\
\hline $\begin{array}{l}\text { DrumPants: An Entire Band in your } \\
\text { Pocket }\end{array}$ & $10 / 01 / 14$ & $\$ 74 \mathrm{k}$ & $\begin{array}{l}\text { Wearable MIDI } \\
\text { controller }\end{array}$ & $\begin{array}{l}\text { World's first industrial quality wearable musical instrument. Watch } \\
\text { someone play it to believe it. }\end{array}$ \\
\hline Ototo: Make Music from Anything & $02 / 03 / 14$ & $£ 73 \mathrm{k}$ & $\begin{array}{l}\text { Maker PCB with synth } \\
\text { and MIDI }\end{array}$ & $\begin{array}{l}\text { Ototo is an all-in-one musical invention kit which allows you to make } \\
\text { an instrument any way you want. }\end{array}$ \\
\hline Pianu - A New Way to Play Piano & $04 / 02 / 15$ & $\$ 59 \mathrm{k}$ & MIDI roll-up keyboard & The fun of Guitar Hero combined with a real musical instrument. \\
\hline $\begin{array}{l}\text { K-Board Pro } 4 \text { - Smart Fabric } \\
\text { Keyboard }\end{array}$ & $21 / 12 / 16$ & $\$ 57 \mathrm{k}$ & $\begin{array}{l}\text { MIDI extended } \\
\text { keyboard controller }\end{array}$ & $\begin{array}{l}\text { K-Board Pro } 4 \text { is an expressive } 4 \text { octave MPE keyboard - a new kind of } \\
\text { controller that feels and responds like a true musical instrument. }\end{array}$ \\
\hline $\begin{array}{l}\text { Musicon - Composing \& Coding for } \\
\text { ages } 3 \text { and up! }\end{array}$ & $30 / 03 / 17$ & $\$ 56 \mathrm{k}$ & $\begin{array}{l}\text { physical acoustic } \\
\text { instrument for children }\end{array}$ & - \\
\hline Kurv Guitar & 23/01/16 & $£ 54 \mathrm{k}$ & $\begin{array}{l}\text { Wireless air guitar } \\
\text { controllers }\end{array}$ & $\begin{array}{l}\text { Kurv is a 'stringless' digital guitar that allows anyone to learn and play } \\
\text { songs using touch, motion and gestures. }\end{array}$ \\
\hline $\begin{array}{l}\text { Skoog 2.0: a new kind of music } \\
\text { interface }\end{array}$ & $06 / 02 / 15$ & $£ 54 \mathrm{k}$ & $\begin{array}{l}\text { tactile instrument with } \\
\text { app and MIDI }\end{array}$ & Wireless Skoog is shipping! Available to order now from [website] \\
\hline $\begin{array}{l}\text { MIDIS - a new breed of musical } \\
\text { instruments }\end{array}$ & $08 / 07 / 15$ & $\vdots € 51 \mathrm{k}$ & $\begin{array}{l}\text { modular MIDI } \\
\text { controllers }\end{array}$ & $\begin{array}{l}\text { Make music in a new and intuitive way at home, in the studio or live on } \\
\text { stage. }\end{array}$ \\
\hline $\begin{array}{l}\text { HyVibe - The World's First Smart } \\
\text { Acoustic Guitar }\end{array}$ & $30 / 12 / 17$ & $\$ 50 \mathrm{k}$ & actuated acoustic guitar & $\begin{array}{l}\text { An acoustic guitar that becomes its own amplifier, connected speaker, } \\
\text { effect processor \& recorder. }\end{array}$ \\
\hline
\end{tabular}




\subsection{Control Paradigm and Physical Form}

22 of the 30 identified instruments are MIDI controllers, which produce symbolic note-level data for a separate synthesis unit. Of these 22 MIDI controllers, 4 of them (Dualo, Ototo, MI Guitar, Lumen) include a built-in hardware synth; the remaining 18 rely on external hardware or software to generate sound, though some come with companion smartphone apps. 3 of 30 instruments (Mogees; Phenol; Hyve) are analog or digital synths using some type of control other than MIDI, though Mogees also supports a MIDI mode, and it is unclear whether Lumen uses MIDI or some other protocol to communicate with its built-in synth. The remaining 5 projects are acoustic instruments (Musicon, Spolum, HyVibe) or actuators for existing acoustic instruments (Vo-96, dadamachines).

24 of the 30 instruments primarily employ note-level control wherein a single action results in a single sound, in the manner of a keyboard, drum kit or other acoustic instrument. (For those instruments which are MIDI controllers without a built-in synth, this determination was made by whether one action produces one MIDI note event.) Of the remaining 6 instruments, 3 (Kordbot, dadamachines, Musicon) use step sequencers or arpeggiators, 2 (Vo-96, Phenol) are based on continuous activation which could be used in a number of different ways, and 1 (HyVibe) is a literal acoustic guitar which could be played in various ways.

11 of 30 instruments explicitly mimic aspects of the form of an existing familiar instrument (Artiphon, jamstik, Oval, Pianu, K-Board, C.24, gTar, MI Guitar, Lumen, Kurv, HyVibe) of which one (Artiphon) is intended to mimic several instrumental forms simultaneously. Overall, 7 instruments are related at least partly to guitar playing (Artiphon, jamstik, gTar, Vo-96, MI Guitar, Kurv, HyVibe) including all four of the top-funded instruments. With the single exception of Musicon, all instruments appear to be primarily designed for solo interaction in the model of a traditional instrument, though most of them could presumably be played within an ensemble.

Some instruments (e.g. Motion Synth) explicitly encode restrictions in the pitch material, for example constraining to diatonic scales, but the nature of the music produced by these instruments is generally left open to the player. None of the 30 instruments primarily take the form of an interactive composition or a conductor system.

\subsection{Marketing}

The text of each crowdfunding campaign page was analysed in terms of its marketing pitch for the product. An inductive approach was used to group the marketing 
into 6 clusters: accessibility, versatility, sensitivity, portability, DIY and education. ${ }^{5}$ The marketing for many instruments fell into more than one cluster.

16 of 30 instruments advertised their accessibility or ease of use, making this the most common marketing pitch. Some descriptions focused on immediate usability: "An intuitive way to create music and play any sound" (Artiphon); "We believe that learning music should be fun and instruments have to be made to be ready to play right away" (Oval); "Above all, it's about everyone making beautiful music out of ordinary objects. Just plug it in and play the world" (Mogees); "Skoog removes the technical barriers to playing an instrument so that you can focus on your sound. You can be expressing yourself musically in less than a minute" (Skoog).

Other descriptions in the accessibility cluster specifically claim that people without prior experience can use the instrument: "The gTar is a fully digital guitar that makes it easy for anybody to play music, regardless of experience" (gTar); "No experience needed; anyone can just pick it up and play" (jamstik); "We believe that anyone can create music, and we want to make our instruments available to everyone" (minim); "If you can use an app, you can use the Motion Synth!" (Motion Synth); "We believe, that anyone can make music and that most of people have talent, which they don't even know about" (Spolum).

14 of 30 instruments advertise their versatility, either in their ability to be used in many musical situations or most often, through the ability to play a wide variety of sounds: "Strum a guitar, bow a violin, tap a piano, loop a beat - on a single instrument. An intuitive way to create music and play any sound" (Artiphon); "A portable guitar that teaches you to play [and] sounds like any musical instrument" (jamstik); "A new electronic musical instrument which allows you to play, learn and perform music using any sound you can imagine" (Oval); "Make music anywhere with any sound, all on one instrument" (Minim); "lets you play any instrument with your voice" (imitone).

Interestingly, all of the instruments advertised this way are MIDI controllers, only one of which contains its own synth. Rather, the advertised feature of being able to play any sound is a function of the external MIDI synth to which they are expected to be connected.

9 of 30 instruments advertise their level of sensitivity or nuance. Instruments in this cluster tend to be targeted at least partly at experienced musicians looking for new modes of expression. "While musicians have drawn an impressive amount of creative expression out of simple switches, these limited interfaces lag far behind the possibilities for subtle control offered by modern synthesizers" (K-Board); "It responds to human touch, even your slightest finger movements give you powerful control" (Hyve); "Its an innovative and evolving instrument simplifying digital music playing and offering beginners and professional artists a unique level of expressivity and spontaneity" (Jouè).

9 of 30 instruments advertise their portability: "Play and compose wherever you want" (Dualo); "Make music anywhere with any sound, all on one instrument"

\footnotetext{
5 These classifications inherently involve subjective decisions on which different analysts may disagree; this analysis is intended to provide an overall sense of the marketing of musical instruments, rather than precise numerical insights.
} 
(Minim). 4 instruments (Mogees, Ototo, Hyve, dadamachines) advertise DIY or user-constructable aspects of the instruments. 2 instruments are targeted at education; one (Pianu) at teaching a traditional instrument, the other (Musicon) at children. Two further projects (Mogees, Skoog) are also targeted partly at children.

\subsection{Discussion}

One of the most striking findings of this survey is the abundance of MIDI controllers (73\% of the sample). Some of these take the physical form of traditional instruments, especially guitar, whereas others are "alternate" controllers (Wanderley and Depalle, 2004), but all but one (KordBot) provide control mainly on a single-note level in a manner similar to a keyboard. Novel MIDI controllers enjoyed a heyday in the 1980's and 1990's, but their regular use in performance seems to have coalesced around a few standard paradigms: piano-style keyboards, drum pads, grid controllers (e.g. Monome, Launchpad, Maschine), wind controllers.

Another notable finding is that many of the MIDI controllers are advertised as enabling anyone to make music, regardless of experience. What this means in practice is further discussed in Section 6, but in the case of note-level MIDI controllers, the claim should be approached with some caution. Musical performance involves skills beyond basic tone production, including rhythmic and melodic skills, which a novice may not yet have developed. It is unclear the extent to which a different geometric configuration in a controller will enable a faster learning curve than a standard keyboard; longitudinal studies on this question would be valuable.

Crowdfunding is typically used as a vehicle to launch new products which often go on to general retail or direct sale. The instruments in this sample all date from 2012 or later, corresponding to the rise of crowdfunding hardware products, and many date from the past 2 years. It is too soon to assess the sustainability of these new instruments, but it will be interesting to see whether they represent a second renaissance in MIDI controller design.

Finally, the heavy tilt toward instruments marketed to general audiences and instruments which offer MIDI keyboard-like capabilities may reflect a form of selection bias. The instruments in this section were chosen based on the most funded Kickstarter and Indiegogo campaigns. It would not be unexpected for instruments marketed to a wide generalist audience to raise more funding than those targeted to specialist or expert communities.

\section{NIME}

The international conference on New Interfaces for Musical Expression (NIME), which began in 2002 (with a CHI workshop of the same name held in 2001), is one of several conferences and journals where musical instrument design for novice 
users has been a focus. See Blaine and Fels (2003) for a review of some of this early work and Miletto et al. (2011) for a more recent perspective. A survey of authors of NIME papers published between 2010 and 2014 (Morreale and McPherson, 2017 ) found that 29 of 70 author-respondents $(41 \%)$ indicated that they made their instrument "for the broader public, including non-musicians."

We surveyed the NIME proceedings between 2012 and 2017, identifying work presented in the paper, poster or demo tracks which introduced new instruments targeted at non-musicians. ${ }^{7}$ In total, we found 31 papers over this 6-year period (out of 693 papers overall) which introduce new interfaces with the explicit purpose of being open to musical novices or general subjects. Of these 31 papers, one (Harriman, 2015) was a review paper. The papers are summarised in Tables 3 and 4.

The decision of which papers to include was made based on title, abstract and a brief review of the text; although we reviewed all papers from 2012-17, we make no claim our selection is comprehensive, and other analysts might choose a different subset. In this section, we deliberately exclude any papers pertaining to music and disability as this topic is covered in Section 5 .

Papers which did not specify who an instrument was intended for were excluded from analysis; a majority of NIME papers did not provide this information, a situation that is further discussed in Section 3.3. Of the 31 papers identified as being relevant, 8 papers (Kountouras and Zannos, 2017; Becking et al., 2016; Jakobsen et al., 2016; Shapiro et al., 2016; Harriman, 2015; Trento and Serafin, 2013; Jensenius and Voldsund, 2012; Trappe, 2012) were aimed at least partly at children, of which 3 (Shapiro et al., 2016; Harriman, 2015; Trappe, 2012) were intended to teach principles of STEM (science, technology, engineering, mathematics). A further 2 papers were aimed at beginning performers of a traditional instrument (flute (Heller et al., 2017), piano (Glickman et al., 2017)). The remaining 16 papers targeted general audiences with limited musical experience. 12 of 31 NIME instruments are specifically designed for multiperson interaction, compared to only 1 of the crowdfunded instruments.

\footnotetext{
${ }^{6}$ This survey question allowed multiple responses, so this does not imply that $41 \%$ of these instruments were solely or even primarily for non-musicians. For example, 58 of $70(82 \%)$ of authors in the survey also indicated that they built the instrument "for myself," and 20 of 70 (29\%) "for musicians generally."

${ }^{7}$ Other conferences where new musical instruments are featured include the International Computer Music Conference, Sound and Music Computing, Computer Music Multidisciplinary Research, and the journals Computer Music Journal and the Journal of New Music Research. For this study, we restricted our search specifically to NIME as it is the largest such venue and one whose aesthetic and technical priorities we wished to study in contrast to HCI venues.
} 
Table 3 Musical instruments for novices or non-musicians published in the NIME proceedings, 2015-17.

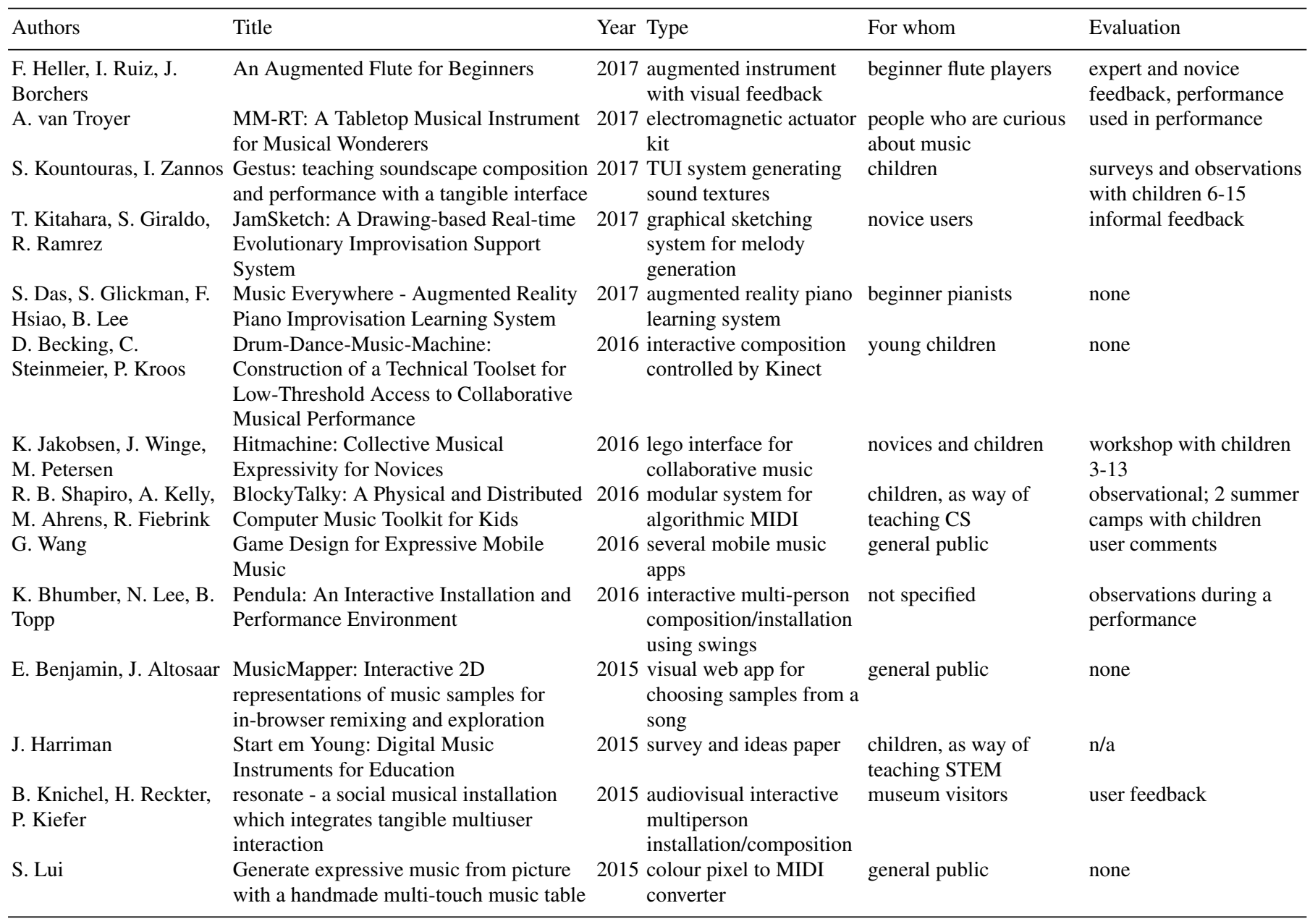


Table 4 Musical instruments for novices or non-musicians published in the NIME proceedings, 2012-14.

\begin{tabular}{|c|c|c|c|c|}
\hline Authors & Title & Year Type & For whom & Evaluation \\
\hline $\begin{array}{l}\text { D. Gabana, A. } \\
\text { McPherson }\end{array}$ & $\begin{array}{l}\text { Radear: A Tangible Spinning Music } \\
\text { Sequencer }\end{array}$ & $\begin{array}{l}2014 \text { looping drum sequencer } \\
\text { based on physical tokens }\end{array}$ & general public & informal feedback \\
\hline $\begin{array}{l}\text { T. Barraclough, J. } \\
\text { Murphy, A. Kapur }\end{array}$ & $\begin{array}{l}\text { New Open-Source Interfaces for } \\
\text { Group-Based Participatory Performance } \\
\text { of Live Electronic Music }\end{array}$ & $\begin{array}{l}2014 \text { remappable MIDI } \\
\text { controllers }\end{array}$ & musicians of all levels & use in an installation \\
\hline $\begin{array}{l}\text { J. Deng, F. Lau, H. Ng, } \\
\text { Y. Kwok, H. Chen, Y. } \\
\text { Liu }\end{array}$ & $\begin{array}{l}\text { WIJAM: A Mobile Collaborative } \\
\text { Improvisation Platform under } \\
\text { Master-players Paradigm }\end{array}$ & $\begin{array}{l}2014 \text { multi-person MIDI note } \\
\text { mobile app system }\end{array}$ & $\begin{array}{l}\text { novice musicians } \\
\text { playing with one master } \\
\text { musician }\end{array}$ & none \\
\hline $\begin{array}{l}\text { H. Diao, Y. Zhou, C. } \\
\text { Harte, N. Bryan-Kinns }\end{array}$ & $\begin{array}{l}\text { Sketch-Based Musical Composition and } \\
\text { Performance }\end{array}$ & $\begin{array}{l}2014 \text { iPad + keyboard to draw } \\
\text { shapes for MIDI events }\end{array}$ & general public & $\begin{array}{l}\text { user study; quantitative } \\
\text { and qualitative }\end{array}$ \\
\hline $\begin{array}{l}\text { Y. Nakanishi, S. } \\
\text { Matsumura, C. Arakawa }\end{array}$ & $\begin{array}{l}\text { B.O.M.B. - Beat Of Magic Box - } \\
\text { Stand-Alone Synthesizer Using Wireless } \\
\text { Synchronization System For Musical } \\
\text { Session and Performance }\end{array}$ & $\begin{array}{l}2014 \text { self-contained Arduino } \\
\text { synths or MIDI } \\
\text { controllers that link } \\
\text { together }\end{array}$ & $\begin{array}{l}\text { musicians and } \\
\text { nonmusicians }\end{array}$ & none \\
\hline $\begin{array}{l}\text { C. Poepel, J. Feitsch, M. } \\
\text { Strobel, C. Geiger }\end{array}$ & $\begin{array}{l}\text { Design and Evaluation of a Gesture } \\
\text { Controlled Singing Voice Installation }\end{array}$ & $\begin{array}{l}2014 \text { video body tracking } \\
\text { vocal synth }\end{array}$ & non-singers & $\begin{array}{l}\text { user study with six } \\
\text { subjects }\end{array}$ \\
\hline $\begin{array}{l}\text { S. Nam, J. Kim, B. } \\
\text { Martinson, M. Helmuth }\end{array}$ & Musical Poi (mPoi) & 2013 self-contained synth & general public & none \\
\hline S. Trento, S. Serafin & $\begin{array}{l}\text { Flag beat: a novel interface for rhythmic } \\
\text { musical expression for kids }\end{array}$ & 2013 rhythm pattern controller & children ages 3-5 & \\
\hline S. Kaneko & $\begin{array}{l}\text { A Function-Oriented Interface for Music } \\
\text { Education and Musical Expressions: "the } \\
\text { Sound Wheel" }\end{array}$ & $\begin{array}{l}2013 \text { harmonic MIDI } \\
\text { controller }\end{array}$ & non-musicians & $\begin{array}{l}\text { questionnaire with } 8 \\
\text { adult subjects }\end{array}$ \\
\hline J. Chui, Y. Tang, M. & SoloTouch: A Capacitive Touch & 2013 pentatonic MIDI & non-musicians & none \\
\hline $\begin{array}{l}\text { Marafa, S. Young } \\
\text { J. Buschert }\end{array}$ & $\begin{array}{l}\text { Controller with Lick-based Note Selector } \\
\text { Musician Maker: Play expressive music } \\
\text { without practice }\end{array}$ & $\begin{array}{l}\text { controller } \\
2012 \text { restricted-scale MIDI } \\
\text { controllers }\end{array}$ & non-musicians & none \\
\hline $\begin{array}{l}\text { C. Frisson, S. Dupont et } \\
\text { al. }\end{array}$ & $\begin{array}{l}\text { LoopJam: turning the dance floor into a } \\
\text { collaborative instrumental map }\end{array}$ & 2012 multi-person installation & general public & use in 3 exhibitions \\
\hline $\begin{array}{l}\text { A. Hansen, H. Andersen, } \\
\text { P. Raudaskoski }\end{array}$ & $\begin{array}{l}\text { Two Shared Rapid Turn Taking Sound } \\
\text { Interfaces for Novices }\end{array}$ & $\begin{array}{l}2012 \text { turn-taking instrument } \\
\text { for pairs of people }\end{array}$ & non-musicians & $\begin{array}{l}\text { comparative study with } \\
\text { children } 10-13\end{array}$ \\
\hline $\begin{array}{l}\text { A. R. Jensenius, A. } \\
\text { Voldsund }\end{array}$ & $\begin{array}{l}\text { The Music Ball Project: Concept, Design, } \\
\text { Development, Performance }\end{array}$ & $\begin{array}{l}2012 \text { ball-shaped simple } \\
\text { musical instruments }\end{array}$ & $\begin{array}{l}\text { general public, including } \\
\text { children }\end{array}$ & informal feedback \\
\hline E. Shahar & $\begin{array}{l}\text { SoundStrand: Composing with a Tangible } \\
\text { Interface }\end{array}$ & $\begin{array}{l}2012 \text { interactive algorithmic } \\
\text { composition }\end{array}$ & general public & none \\
\hline C. Trappe & $\begin{array}{l}\text { Making Sound Synthesis Accessible to } \\
\text { Children }\end{array}$ & $\begin{array}{l}2012 \text { block-based GUI for } \\
\text { algorithmic music }\end{array}$ & children & $\begin{array}{l}\text { workshops with children } \\
9-10\end{array}$ \\
\hline F. Zamorano & $\begin{array}{l}\text { Simpletones: A System of Collaborative } \\
\text { Physical Controllers for Novices }\end{array}$ & $\begin{array}{l}2012 \text { collaborative instrument } \\
\text { for algorithmic music }\end{array}$ & non-musicians & none \\
\hline
\end{tabular}




\subsection{Control Paradigm and Physical Form}

Compared to the crowdfunded instruments, NIME shows a wider diversity of instrumental forms and behaviours. 12 of 31 instruments are MIDI controllers or sequencers. 7 of 31 instruments are self-contained synths (1 overlap with the MIDI controllers (Nakanishi et al., 2014)). 3 of 31 (Heller et al., 2017; van Troyer, 2017; Glickman et al., 2017) are either augmented or acoustic instruments. 6 of 31 projects (van Troyer, 2017; Jakobsen et al., 2016; Shapiro et al., 2016; Barraclough et al., 2014; Diao et al., 2014; Trappe, 2012) are designed as platforms or toolkits for performers to create their own instruments.

While 24 of the 30 crowdfunded instruments featured control on an individual note level, only 6 of the NIME instruments primarily work this way. Instead, 10 of 31 projects are interactive compositions or installations, and 5 of 31 (van Troyer, 2017; Arellano and McPherson, 2014; Nakanishi et al., 2014; Trento and Serafin, 2013; Frisson et al., 2012) are based on manipulating loops. The remainder use a variety of different control metaphors, including programmable algorithmic behaviour (Shapiro et al., 2016).

15 of 31 instruments are based on tangible interaction, either through tabletops (e.g. van Troyer (2017)), interconnectable physical blocks (Jakobsen et al., 2016; Shapiro et al., 2016) or other novel physical interfaces (e.g. Nam (2013)). By contrast, 9 of 31 are screen or mobile-device based. 3 instruments (Becking et al., 2016; Poepel et al., 2014; Frisson et al., 2012) use full-body interaction while 1 (Glickman et al., 2017) involves augmented reality.

These papers were selected for their explicit focus on musical novices. Several, though not all, of the papers address the question of how to provide appropriate forms of control for this population. 6 papers seek to improve accessibility by removing the possibility for error in the form of "wrong notes" or, in some cases, timing asynchrony. The typical approach restricts the pitch material to a (usually selectable) diatonic or pentatonic scale.

Many of the instruments provide visual or tactile feedback. Within this set, 5 instruments have cross-modal mappings at their core, for example generating music from visual material (Lui, 2015; Kitahara et al., 2017) or letting the user create their own visual interface for music creation (Diao et al., 2014).

\subsection{Evaluation Methods}

Where crowdfunding campaigns are driven by commercial incentives, published papers tend to focus on contributions to knowledge. This means that where Kickstarter campaigns target potential customers, NIME papers are more likely to be addressed at peer researchers rather than potential users. Evaluation of new musical instruments is a persistently challenging topic, a summary of which is beyond the scope of this chapter. For a larger context of evaluation in the NIME community, see Barbosa et al. (2015), which finds that during the 2012-2014 conferences, $44 \%$ 
of NIME papers included some form of evaluation (excluding those papers where evaluation was determined to be not applicable).

Of 30 papers considered here (excluding the review article (Harriman, 2015)), 8 included a systematic user study including qualitative or quantitative metrics. A further 11 papers included either informal user feedback (6 papers) or self-observations by the author from deployment in performance or installation contexts (6 papers; 1 overlap). 11 of 30 papers contained no explicit evaluation.

\subsection{Discussion}

While making musical experiences for non-musicians has a long history in NIME and related communities, in the 2012-17 period, only 31 of 693 papers (4.5\%) explicitly focus on this question. It is possible that the topic is becoming less prevalent as time goes on, though the survey of 2010-14 authors which found that $41 \%$ built their instruments at least in part for the general public (in contrast to another category, "musicians generally") suggests otherwise (Morreale and McPherson, 2017).

It may be that many authors simply do not indicate in their paper for whom the instrument is built, or that its usability by the general public is secondary to its suitability for experienced musicians. Just as the guitar can be suitable for both experts and non-musicians, some NIME instruments designed for experienced performers have gone on to be used by novices (Ferguson and Wanderley, 2010). More generally, unlike crowdfunding campaigns, academic papers are not intended to market the product itself. Indeed, it is notable that most of the papers in our sample have at least one other stated research goal. These include group interaction, tangible interfaces, childhood education and cross-modal mapping. In most cases, the papers focus on technical attributes of instrument design, rather than social or cultural factors that might explain how to address the needs of one particular community.

Together, these observations suggest that creating musical interfaces for nonmusicians may not be the primary end unto itself in many recent papers, but rather a compelling test case for exploring other engineering and HCI research questions. The observations also mean that the selection of papers considered here may not be entirely representative, as some instruments suitable for novices could be left out if the authors did not specify the intended user community. An alternative for the present study could have been to use our own judgment about whether an interface might be suitable for non-musicians - indeed, reading many NIME papers, it seems reasonable that the device is intended for non-musicians even if the authors never specify this - but this would have introduced a different and perhaps more problematic bias than relying on the authors' own words.

One contrast between NIME and crowdfunding that is likely to persist for any sample of NIME instruments is the frequency with which interactive compositions appear at NIME. This offers an alternative artistically-driven motivation for creating interfaces for non-musicians, though one perhaps focused more on the aesthetic pri- 
orities of the creator than those of the user. The implications of creating interactive compositions as musical instruments will be discussed further in Section 6.

\section{Human-Computer Interaction}

The NIME conference originated as a workshop at CHI 2001 (the ACM SIGCHI Conference on Human Factors in Computing Systems), and NIME has retained links with HCI in the ensuing years (evidenced in part by the current book). Still, the values and methods in HCI need not be the same as those in the specialist community devoted to musical instruments.

In this section we review new musical instruments presented since 2012 at several high-profile ACM SIGCHI conferences in Human-Computer Interaction: Human Factors in Computing Systems (CHI), Tangible and Embodied Interaction (TEI), User Interface Software and Technology (UIST) and Creativity \& Cognition $(\mathrm{C} \& \mathrm{C}) .{ }^{8}$ Full papers, posters, and interactive demos were considered as long as they were included in the published proceedings (including $\mathrm{CHI}$ Extended Abstracts). 10 papers were identified which introduce an instrument aimed at novice audiences; these are shown in Table 5.

${ }^{8}$ The regional conferences $\mathrm{OzCHI}$ and NordiCHI were also surveyed, though no similar works were identified there. 
Table 5 Musical instruments presented at relevant ACM SIGCHI conferences 2012-2017.

\begin{tabular}{|c|c|c|c|c|c|}
\hline Authors & Title & Conference & Type & For whom & Evaluation \\
\hline K. Klipfel & $\begin{array}{l}\text { MIDI Motion: Interactive Music } \\
\text { Composition Glove }\end{array}$ & TEI 2017 & $\begin{array}{l}\text { Hand gesture MIDI } \\
\text { controller }\end{array}$ & not specified & none \\
\hline $\begin{array}{l}\text { F. Lyu, F. Tian, W. Feng, } \\
\text { X. Cao, X.L. Zhang, G. } \\
\text { Dai, and H. Wang }\end{array}$ & $\begin{array}{l}\text { EnseWing: Creating an Instrumental } \\
\text { Ensemble Playing Experience for } \\
\text { Children with Limited Music Training }\end{array}$ & CHI 2017 & $\begin{array}{l}\text { Gesture-based } \\
\text { conductor system }\end{array}$ & children & field study \\
\hline $\begin{array}{l}\text { G. Chuang, S. Wang, S. } \\
\text { Burns, O. Shaer. }\end{array}$ & EmotiSphere: From Emotion to Music & TEI 2015 & $\begin{array}{l}\text { Mixed-initiative } \\
\text { tangible installation }\end{array}$ & general public & none \\
\hline $\begin{array}{l}\text { N. Schnell, S. } \\
\text { Robaszkiewicz, F. } \\
\text { Bevilacqua, D. Schwarz }\end{array}$ & $\begin{array}{l}\text { Collective Sound Checks: Exploring } \\
\text { Intertwined Sonic and Social Affordances } \\
\text { of Mobile Web Applications }\end{array}$ & TEI 2015 & $\begin{array}{l}\text { Mobile web app, } \\
\text { triggers sounds }\end{array}$ & general public & none \\
\hline $\begin{array}{l}\text { B. Bengler, N. } \\
\text { Bryan-Kinns }\end{array}$ & $\begin{array}{l}\text { Designing collaborative musical } \\
\text { experiences for broad audiences }\end{array}$ & C\&C 2013 & $\begin{array}{l}\text { Tangible MIDI } \\
\text { controller }\end{array}$ & general public & $\begin{array}{l}\text { questionnaire and } \\
\text { observations at a } \\
\text { public event }\end{array}$ \\
\hline G. Griffin, R. Jacob & $\begin{array}{l}\text { Priming Creativity Through } \\
\text { Improvisation on an Adaptive Musical } \\
\text { Instrument }\end{array}$ & C\&C 2013 & $\begin{array}{l}\text { Virtual instrument } \\
\text { controller }\end{array}$ & general public & experimental study \\
\hline $\begin{array}{l}\text { A. Tanaka, B. } \\
\text { Caramiaux, N. Schnell }\end{array}$ & $\begin{array}{l}\text { MubuFunkScatShare: Gestural Energy } \\
\text { and Shared Interactive Music }\end{array}$ & CHI 2013 & $\begin{array}{l}\text { Mobile-gesture } \\
\text { controlled } \\
\text { instrument }\end{array}$ & $\begin{array}{l}\text { trained performers and } \\
\text { novices }\end{array}$ & none \\
\hline $\begin{array}{l}\text { F. Morreale, R. Masu, A. } \\
\text { De Angeli, P. Rota }\end{array}$ & The Music Room & CHI 2013 & $\begin{array}{l}\text { Mixed-initiative } \\
\text { interactive } \\
\text { installation }\end{array}$ & general public & $\begin{array}{l}\text { questionnaire and } \\
\text { observations at a } \\
\text { public event }\end{array}$ \\
\hline F. Zamorano & $\begin{array}{l}\text { SimpleTones: A Collaborative Sound } \\
\text { Controller System for Non-Musicians }\end{array}$ & CHI 2013 & $\begin{array}{l}\text { Tangible MIDI } \\
\text { controller }\end{array}$ & general public & none \\
\hline $\begin{array}{l}\text { L. Dahl, S. } \\
\text { Robaszkiewicz }\end{array}$ & $\begin{array}{l}\text { For Novices Playing Music Together, } \\
\text { Adding Structural Constraints Leads to } \\
\text { Better Music and May Improve User } \\
\text { Experience }\end{array}$ & UIST 2012 & $\begin{array}{l}\text { two-person } \\
\text { screen-based } \\
\text { instrument }\end{array}$ & non-musicians & experimental study \\
\hline
\end{tabular}




\subsection{Objective}

In 7 of 10 cases the objective of the system seems to be enabling those without musical skills to "create music and express themselves" (Chuang et al., 2015). Of these, only EmotiSphere is intended to be used individually; in 5 other cases, (Bengler and Bryan-Kinns, 2013; Morreale et al., 2013; Griffin and Jacob, 2013; Zamorano, 2013; Dahl and Robaszkiewicz, 2012), the experience of collaboratively creating music is an end unto itself, enabling people without particular musical training to experience being part of a collaborative creative musical process. The last system of this set, EnseWing (Lyu et al., 2017), is designed to offer children the experience of playing in an ensemble.

A common theme that brings together most of these 7 works is the focus on playful and social aspects of the experience, which seem more imporant than the musical output. SimpleTones users reported that they were playing rather than performing (Zamorano, 2013). Similarly, the visitors of The Music Room (Morreale et al., 2013) described their experience as engaging, intimate, and playful. Half of them reported feelings of being immersed in the experience and following the music rather than actually controlling it (Morreale and De Angeli, 2015). An exception is Dahl and Robaszkiewicz (2012), where musical output quality is explicitly evaluated.

The remaining three instruments are more focused on the actual performance. This is the case of MubuFunkScatShare, in which the collaborative aspect serves to enable novices to explore musical material created by musically trained performers (Tanaka et al., 2013). The focus on music performance is also present in MIDI Motion (Klipfel, 2017), whose aim is to make music performance more intuitive and less complicated for users not familiar with musical concepts, and in Collective Sound Check (Schnell et al., 2015), which aims to facilitate spontaneous collective performances.

\subsection{Control Paradigm}

Notably, in all 10 cases, part of the musical agency is delegated to the computer, reducing user responsibility in the process of music creation. In 3 of 10 cases (Griffin and Jacob, 2013; Zamorano, 2013; Klipfel, 2017) the user can control the sound at note level while the system encodes some sort of restrictions in the pitches that can be played: the user can only choose from a subset of the chromatic scale in an effort by the system to keep the output harmonious. By contrast, Collective Sound Check (Schnell et al., 2015) and EnseWing (Lyu et al., 2017) are conductor systems: the user does not have to worry about playing the correct pitch but can instead control rhythmic patterns and dynamics.

A different sort of constraint is employed in The Music Room (Morreale et al., 2013) and EmotiSphere (Chuang et al., 2015), both mixed-initiative interfaces in which the music is mostly composed by an algorithmic system, leaving users highlevel control on the emotional character of the composition (in The Music Room the 
users can deliberately influence the emotional character, whereas in EmotiSphere it is sensed through physiological sensing). The authors justify these design choices in the light of simplifying access to music creation while, at the same time, allowing users to explore and enjoy improvisation with sound in a similar fashion as trained musicians would, letting them actively participate in the social aspects of collective musical improvisation, something usually confined to trained performers (Zamorano, 2013).

Other distinct types of control are offered by Polymetros (Bengler and BryanKinns, 2013), which uses a step sequencer metaphor, and MubuFunkScatShare (Tanaka et al., 2013), which allows users to manipulate pre-recorded sonic material by means of concatentative synthesis.

\subsection{Evaluation}

A surprising finding amongst the $\mathrm{HCI}$ instruments is that only half of the papers (5 of 10) contained any form of evaluation, a smaller proportion than the NIME papers (where 63\% contained at least observational feedback). Given the sample sizes and the fact that many of the HCI papers are quite short (e.g. accompanying conference demos), the significance of this difference is unclear. Since NIME has frequently borrowed evaluation methods from HCI (Wanderley and Orio, 2002; Kiefer et al., 2008), this finding suggests that a bidirectional exchange of evaluation ideas might be fruitful.

More generally, the intended aim of most instruments seems to be to provide the general public with novel experiences of music-making for exploratory and experiential purposes. These goals are similar to those of many of the NIME instruments, and the approach taken in most cases could be equally at home at NIME or other music technology conferences. In fact, 6 of 10 first authors and at least one author for 7 of 10 papers have also published at NIME, including one project (Zamorano, 2013, 2012) which is published in both categories.

\section{Accessible Instruments for Disability}

The term 'accessible instruments' is often used to refer to musical instruments designed for use by disabled people. Within this category, a distinction can be drawn between accessible instruments designed to enable virtuosic or masterful performances by physically disabled musicians (here referred to as 'performance-focused instruments'), and those designed to elicit the therapeutic or wellbeing aspects of music making for disabled people with physical and cognitive impairments and learning difficulties, who may be identified as 'non-musicians'. Here we refer to the latter case as 'therapeutic instruments', referring to the design goals of enabling 
musicking for wellbeing purposes, and not necessarily solely for use in formal music therapy.

While many performance-focused accessible instruments require similar learning trajectories as traditional or unadapted instruments (see David Nabb's togglekey saxophone ${ }^{9}$ or John Kelly's Kellycaster guitar ${ }^{10}$ ), therapeutic instruments often require the ability to 'skip ahead' past the acquisition of musical and instrumental skill in order to focus on the therapeutic aspects of musical participation. In this section we discuss those accessible instruments for which ease-of-use and low barrier to music-making are a key design feature, rather than the ability to give masterful or virtuosic performances. We selected instruments based on two design criteria: enabling devices for people with physical or cognitive impairments and learning difficulties, and an explicit aim to make musical performance and participation 'easy'.

There exist a small number of reviews of and frameworks for Accessible Instrument design within NIME and related fields. Ward et al. (2017) provide a number of design principles for instruments for users with complex needs in Special Educational Needs (SEN) settings. Hunt et al. (2004) discuss topics relating to the use of music technology in music therapy settings. Larsen et al. (2016) and Graham-Knight and Tzanetakis (2015) provide reviews of existing instruments from academia and commercial products, from music therapy contexts and others.

\subsection{Commercial Products}

\footnotetext{
${ }^{9} \mathrm{http}: / /$ www.unk.edu/academics/music/unk-one-handed-winds-program.php

10 http://cdm.link/2017/09/take-a-look-at-the-kellycaster-a-unique-and-accessible-instrumentbuilt-by-dmlabs/
} 
Table 6 Commercially available Accessible Therapeutic Instruments

\begin{tabular}{|c|c|c|c|}
\hline Name & Description & Marketing & Website \\
\hline Soundbeam & $\begin{array}{l}\text { Mid-air gesture sensing and tactile } \\
\text { switches }\end{array}$ & $\begin{array}{l}\text { Disabled people in SEN schools and } \\
\text { orchestras }\end{array}$ & http://www.soundbeam.co.uk/ \\
\hline Skoog & $\begin{array}{l}\text { Malleable foam cube and accompanying } \\
\text { software }\end{array}$ & $\begin{array}{l}\text { Disabled people in SEN schools and } \\
\text { orchestras, beginner musicians, } \\
\text { experienced electronic musicians, } \\
\text { families }\end{array}$ & http://skoogmusic.com/ \\
\hline Clarion & $\begin{array}{l}\text { PC/iPad software designed for use with } \\
\text { existing AT devices }\end{array}$ & Disabled people in orchestras & https://www.openorchestras.org/instruments/ \\
\hline Apollo Ensemble & $\begin{array}{l}\text { PC sensor-to-sound mapping software } \\
\text { and range of hardware sensors }\end{array}$ & $\begin{array}{l}\text { Disabled people in SEN settings and } \\
\text { general music making }\end{array}$ & http://www.apolloensemble.co.uk/ \\
\hline Beamz & $\begin{array}{l}4 \text { or } 6 \text { beam 'laser harp' and } \\
\text { accompanying software }\end{array}$ & $\begin{array}{l}\text { Disabled people in SEN and music } \\
\text { therapy settings, general music making, } \\
\text { experienced musicians }\end{array}$ & http://www.thebeamz.com/ \\
\hline
\end{tabular}


We identified five commercially available products which fit our survey criteria for Accessible Therapeutic Instruments (Table 6), of which one (version 2.0 of the Skoog), was also crowdfunded (see Section 2). All five products are marketed for use by children and adults with learning disabilities or difficulties or physical impairments. They all follow a similar format, consisting of an accessible interface paired with proprietary software for sound production, either via in-software sounds or MIDI routing for use with DAWs and software instruments.

\subsubsection{Form}

The Soundbeam and Beamz make use of mid-air gestures to trigger events, using optical sensors (Beamz) or ultrasonic sensors (Soundbeam). The Skoog and Ensemble use tactile switches and sensors. The Skoog is a deformable foam cube with a three-dimensional position sensor at the core ${ }^{11}$, allowing for simple interactions like pressing one side of the cube, or more complex ones such as shaking or twisting. Ensemble focuses on offering a broad range of interaction modes in order to adapt to a range of physical abilities. Apollo's own wireless sensor modules include switches, rotation ('Dice') and RFID sensors, but the system is designed to be used with game controllers, accessibility switches and MIDI or OSC devices. The Clarion is a PC or tablet software program that allows users to design their own on-screen note-triggering areas which can be accessed via cursor control or touchscreen interaction. It is designed to make use of existing Assistive Technology (AT) hardware such as eye gaze and head tracking devices.

\subsubsection{Interaction Modes}

Of the five products surveyed, two offered only note or event triggering with no additional modulation (Soundbeam and Beamz). Beamz features either four or six event triggering spaces, so is most commonly used to cycle through pre-defined note sequences or trigger samples. Moving the hand towards or away from the sensors continuously has no effect. Soundbeam allows for note selection based on proximity to the sensor, so note sequences can be improvised as well as pre-defined. Apollo and Clarion offer some continuous control over modulation: a continuous sensor such as the 'Dice' module can be mapped to a MIDI control channel in the Apollo Ensemble software, and the position of the cursor within the on-screen region can be mapped to continuous modulation in Clarion. Both Apollo and Clarion opt for user-configurability, allowing for various configurations of hardware and mappings. Skoog's Skoogmusic software allows the continuous data from the sensor to be used to modulate various software instrument's physical modelling parameters (for example overblow or harmonic effects in wind instruments). These can also be adjusted

\footnotetext{
${ }^{11} \mathrm{https} / / /$ www.soundonsound.com/reviews/skoogmusic-skoog
} 
and re-mapped depending on the user's motor ability, allowing for note triggering thresholds to be individual set for each side of the cube

\subsubsection{Marketing and Target Audiences}

Both Skoog and Beamz are marketed at wide audiences, although Skoog's promotional material places its accessibility and ease-of-use more prominently. Beamz appears to be aimed at music therapists and disabled people, but is also marketed towards musicians and people interested in interactive music applications. Apollo, Clarion and Soundbeam are more explicitly marketed towards disabled people. Four of the products included music therapy in their proposed use cases. All five products offer some form of accompanying educational material for use in schools and SEN settings.

\subsection{NIME and Related Research}


Table 7 Accessible Therapeutic Instruments from NIME and related research

\begin{tabular}{|c|c|c|c|c|}
\hline Authors & Title & Year Type & For whom & Evaluation \\
\hline A. Nath, S. Young & $\begin{array}{l}\text { VESBALL : A ball-shaped instrument for } \\
\text { music therapy }\end{array}$ & $\begin{array}{l}2015 \text { malleable foam based } \\
\text { music controller }\end{array}$ & $\begin{array}{l}\text { Autistic children using } \\
\text { music therapy }\end{array}$ & $\begin{array}{l}\text { no formal evaluation } \\
\text { stated, work is ongoing }\end{array}$ \\
\hline $\begin{array}{l}\text { S. Katan, M. Grierson, } \\
\text { R. Fiebrink }\end{array}$ & $\begin{array}{l}\text { Using Interactive Machine Learning to } \\
\text { Support Interface Development Through } \\
\text { Workshops with Disabled People }\end{array}$ & $\begin{array}{l}2015 \text { mapping several } \\
\text { interfaces to music } \\
\text { software using machine } \\
\text { learning }\end{array}$ & $\begin{array}{l}\text { disabled people } \\
\text { interested in general } \\
\text { music making }\end{array}$ & $\begin{array}{l}\text { observation of users } \\
\text { during workshops }\end{array}$ \\
\hline A. Jense, H. Leeuw & $\begin{array}{l}\text { WamBam : A case study in design for an } \\
\text { electronic musical instrument for } \\
\text { severely intellectually disabled users }\end{array}$ & $\begin{array}{l}2015 \text { electronic hand-drum } \\
\text { with vibrotactile } \\
\text { feedback }\end{array}$ & $\begin{array}{l}\text { learning disabled people } \\
\text { using music therapy }\end{array}$ & $\begin{array}{l}\text { observation of use } \\
\text { within music therapy } \\
\text { sessions }\end{array}$ \\
\hline $\begin{array}{l}\text { B. Cappelen, A. } \\
\text { Andersson }\end{array}$ & $\begin{array}{l}\text { Designing four generations of } \\
\text { 'Musicking Tangibles' }\end{array}$ & $\begin{array}{l}2014 \text { malleable, tangible } \\
\text { multisensory interfaces } \\
\text { and environments }\end{array}$ & $\begin{array}{l}\text { families with children } \\
\text { with learning disabilities }\end{array}$ & $\begin{array}{l}\text { participatory design/case } \\
\text { study approach }\end{array}$ \\
\hline $\begin{array}{l}\text { J. Larsen, D. Overholt, } \\
\text { T. Moeslund }\end{array}$ & $\begin{array}{l}\text { The actuated guitar: Implementation and } \\
\text { user test on children with hemiplegia }\end{array}$ & $\begin{array}{l}2014 \text { electric guitar with } \\
\text { strumming mechanism } \\
\text { and accessible foot } \\
\text { controller }\end{array}$ & $\begin{array}{l}\text { children with hemiplegic } \\
\text { cerebral palsy, } \\
\text { potentially using music } \\
\text { therapy for motor } \\
\text { exercises }\end{array}$ & $\begin{array}{l}\text { semi-structured } \\
\text { interviews and } \\
\text { observation of musical } \\
\text { tasks }\end{array}$ \\
\hline M. Grierson, C. Kiefer & $\begin{array}{l}\text { NoiseBear: A Malleable Wireless } \\
\text { Controller Designed In Participation with } \\
\text { Disabled Children }\end{array}$ & $\begin{array}{l}2014 \text { Malleable wireless } \\
\text { controller for music } \\
\text { software }\end{array}$ & $\begin{array}{l}\text { autistic children in SEN } \\
\text { settings }\end{array}$ & $\begin{array}{l}\text { participatory design, } \\
\text { observation of sessions } \\
\text { with teacher }\end{array}$ \\
\hline S. Favilla, S. Pedell & $\begin{array}{l}\text { Touch Screen Collaborative Music: } \\
\text { Designing NIME for Older People with } \\
\text { Dementia }\end{array}$ & $\begin{array}{l}2014 \text { iPad based conductor } \\
\text { system using touchOSC } \\
\text { and MIDI performances }\end{array}$ & $\begin{array}{l}\text { older people with } \\
\text { dementia using music } \\
\text { therapy }\end{array}$ & $\begin{array}{l}\text { observation of music } \\
\text { therapy sessions, } \\
\text { recording and analysis } \\
\text { of touch screen data }\end{array}$ \\
\hline $\begin{array}{l}\text { D. Meckin, N. } \\
\text { Bryan-Kinns }\end{array}$ & $\begin{array}{l}\text { moosikMasheens : Music, Motion and } \\
\text { Narrative with Young People who have } \\
\text { Complex Needs }\end{array}$ & $\begin{array}{l}2013 \text { actuated guitar, } \\
\text { glockenspiel and drum } \\
\text { stick with iPad interface }\end{array}$ & $\begin{array}{l}\text { learning and physically } \\
\text { disabled people in group } \\
\text { music making SEN } \\
\text { settings }\end{array}$ & $\begin{array}{l}\text { participatory design } \\
\text { approach, observations } \\
\text { during music workshops }\end{array}$ \\
\hline $\begin{array}{l}\text { M. Luhtala, T. } \\
\text { Kymalainen, J. Plomp }\end{array}$ & $\begin{array}{l}\text { Designing a Music Performance Space } \\
\text { for Persons with Intellectual Learning } \\
\text { Disabilities }\end{array}$ & $\begin{array}{l}2011 \text { Guitar Hero controllers } \\
\text { for cycling through note } \\
\text { sequences, triggering } \\
\text { chords or note events }\end{array}$ & $\begin{array}{l}\text { learning disabled people } \\
\text { using group music } \\
\text { therapy }\end{array}$ & $\begin{array}{l}\text { observations during use } \\
\text { in group music therapy, } \\
\text { semi-structured } \\
\text { interviews with users }\end{array}$ \\
\hline S. Bhat & $\begin{array}{l}\text { TouchTone: an electronic musical } \\
\text { instrument for children with hemiplegic } \\
\text { cerebral palsy }\end{array}$ & $\begin{array}{l}2010 \text { keyboard based interface } \\
\text { with pentatonic scales } \\
\text { and large modifier } \\
\text { button for affected limb }\end{array}$ & $\begin{array}{l}\text { children with cerebral } \\
\text { palsy using music } \\
\text { therapy }\end{array}$ & $\begin{array}{l}\text { observation of musical } \\
\text { tasks }\end{array}$ \\
\hline $\begin{array}{l}\text { C. Tam, H. Schwellnus, } \\
\text { C. Eaton et al. }\end{array}$ & $\begin{array}{l}\text { Movement-to-music computer } \\
\text { technology: A developmental play } \\
\text { experience for children with severe } \\
\text { physical disabilities }\end{array}$ & $\begin{array}{l}2007 \text { webcam-based } \\
\text { note/event triggering } \\
\text { software }\end{array}$ & $\begin{array}{l}\text { children with severe } \\
\text { physical disabilities } \\
\text { using music therapy }\end{array}$ & $\begin{array}{l}\text { post-intervention } \\
\text { analysis of interviews }\end{array}$ \\
\hline
\end{tabular}


This section concerns instruments coming from accessible instrument research, which both fit our 'therapeutic instrument' criteria and focus on ease-of-use and access for non-musicians. This is not a comprehensive survey of all accessible instrument research and NIME research related to disability, but only those papers which describe novel instruments or interfaces for disabled musicians which share similar 'low barrier to entry' goals as those described elsewhere in this chapter (Wessel and Wright, 2002). We include papers from other conferences and journals related to NIME, where a novel instrument or adaptation is described. These include: International Computer Music Conference (ICMC), CHI, IEEE Multimedia, Interaction Design and Children (IDC), 'Music, Health Technology and Design', and Occupational Therapy International

\subsubsection{Form}

Of the eleven papers we surveyed which fit our criteria, four described malleable, fabric based pressure sensitive interfaces (Nath and Young, 2015; Katan et al., 2015; Cappelen and Andersson, 2014; Grierson and Kiefer, 2013b), two featured actuated instruments with accessible interfaces (Larsen et al., 2014; Meckin and Bryan-kinns, 2013), two featured webcam or Kinect based interactions (Katan et al., 2015; Tam et al., 2007), one was a keyboard based controller (Bhat, 2010), another was based on a hand drum (Jense and Leeuw, 2015) and one featured a touch screen interface (Favilla and Pedell, 2014). Two describe the use of game controllers to trigger sounds (Katan et al., 2015; Luhtala et al., 2011). Katan et al. (2015) also describe using mid-air gesture sensors such as Leapmotion.

Unlike the commercially available products, instruments in this set deviated from the 'interface plus host software' paradigm, with half of the papers describing selfcontained units with no requirement for an external speaker (not including Larsen et. al's actuated electric guitar which is an acoustic instrument but requires external amplification).

\subsubsection{Interaction Modes}

Larsen et al. (2014) describe a fairly complex mode of interaction, in which users with hemiplegic cerebral palsy fret guitar strings with their unaffected limb and trigger a strumming mechanism via a foot switch. This requires a greater level of instrumental and musical skill for fretting, as the users are not constrained to only pleasing sounds and scales. The instrument is clearly aimed at non-musicians or novices however, as the strings are tuned to an open tuning to allow simple barre chords, and frets are colour coded with an accompanying colour-based score.

Only the WamBam (Jense and Leeuw, 2015) and TouchTone (Bhat, 2010) resembled traditional MIDI-controllers, with note-level control using discrete keys or switches. The moosikMasheens project (Meckin and Bryan-kinns, 2013) has a relatively simple mode of interaction, which is based on touching regions of a touch- 
screen interface in order to trigger notes or sequences on the actuated acoustic instruments. Favilla and Pedell (2014) also describe a touchscreen-based interaction, using discrete on-screen buttons and $\mathrm{X} / \mathrm{Y}$ pads created using the touchOSC app. These were used to trigger and modify abstract synthetic sounds, and then to modulate performance parameters of a MIDI performance of Bach's Goldberg Variations. Luhtala et al. (2011) use Guitar Hero controllers to step through note sequences, trigger pre-defined chords, or trigger notes from a pre-set scale or arpeggio.

Katan et al. (2015) describe a number of hardware interfaces including webcams, Kinects and game controllers, mapped to music software via the Interactive Machine Learning software Wekinator (Fiebrink, 2010). This allowed users to rapidly prototype various mappings and interaction modes by using Wekinator to 'learn' their preferred gestures. Wekinator is discussed further in Rebecca Fiebrink's interview in Chapter 16 of this book (Holland and Fiebrink, 2019).

\subsubsection{Use Cases, Target Audiences and Evaluation}

6 of 11 papers mentioned music therapy explicitly as an intended use case and method of evaluation (Nath and Young, 2015; Bhat, 2010; Tam et al., 2007; Jense and Leeuw, 2015; Favilla and Pedell, 2014; Luhtala et al., 2011). Two mentioned music therapy implicitly (as either a potential use case or a motivation for design) (Cappelen and Andersson, 2014; Larsen et al., 2014). Two were concerned with music education in SEN settings (Grierson and Kiefer, 2013b; Meckin and Bryankinns, 2013), while one paper was concerned with enabling general music making activities for disabled people (Katan et al., 2015).

The target audiences for these papers were predominantly children. Three papers mentioned children with learning disabilities as their target audiences (Nath and Young, 2015; Grierson and Kiefer, 2013a; Meckin and Bryan-kinns, 2013), two of which were explicitly aimed at autistic children. One paper included families with children with learning disabilities (Cappelen and Andersson, 2014). Two included children with only physical disabilities (Larsen et al., 2014; Bhat, 2010). Three papers described instruments intended for adults with learning disabilities (Katan et al., 2015; Luhtala et al., 2011; Jense and Leeuw, 2015), and one described a system for older people with dementia (Favilla and Pedell, 2014).

Most papers featured an evaluation of the instrument, which was typically based on observations during their use in music lessons or music therapy sessions (eight of eleven papers). One paper included analysis of touchscreen data captured during therapy sessions (Favilla and Pedell, 2014). Three used a participatory design case study approach for both developing the instrument and evaluation (Cappelen and Andersson, 2014; Grierson and Kiefer, 2013a; Meckin and Bryan-kinns, 2013). 


\subsection{Comparison of Commercial and NIME Instruments}

Common to all five commercial products was the ability to play a large variety of sounds, and calibrate or configure the interface to suit a wide range of users. This reflects the fact that in music therapy and SEN settings (the markets at which these products are mostly aimed), clients or students will have a wide range of physical abilities, musical tastes, and cognitive development. For cost and practicality reasons, it would be desirable to use a single device which can be adapted to suit a user's needs. At the same time, the focus on variety of sounds is also found in other crowdfunded instruments not explicitly designed for accessibility.

Most of the five commercial devices do not use the MIDI protocol to communicate with their proprietary software, but they all follow the 'interface plus host software' paradigm: none of the instruments are restricted to any one sound scheme, and none produce sound acoustically or via inbuilt amplification. While some of the most successful performance-focused accessible instruments are bespoke designs, built for a single users' needs (for example, many of the instruments supported by the One-Handed Musical Instrument Trust's annual awards ${ }^{12}$ ), specialised devices for a single user are not feasible in many contexts in which therapeutic instruments might be used.

When comparing NIME and related research to commercially available instruments marketed for similar accessibility use cases, what is most striking is the breadth of form and interaction modality within the former group. More idiosyncratic interfaces appear within this subset, from actuated electronic instruments to interactive furniture installations with abstract shapes. This perhaps represents the results of exploratory and participatory design processes, where commercial viability is not such an issue, and discovering novel methods of improving interaction with music for this audience is a key design goal. That said, the flexibility of many of the instruments within this group is greatly reduced due to single modes of interaction and reduced sound sets. Again this could reflect the lack of a need for commercial viability, or as a result of a participatory design process for a single group with similar needs.

\section{Discussion}

The four preceding sections show that interest remains high in creating musical instruments aimed at non-musicians. Collectively, these papers and products represent over 80 instrument designs, most of which date from the past 6 years. Moreover, earlier references (Paradiso, 1999; Robson, 2001; Blaine and Fels, 2003) show that this goal is not a new one, so it is likely that there have been hundreds of attempts to address this particular topic in the period since real-time digital synthesis became widely available.

\footnotetext{
12 http://www.ohmi.org.uk/ohmi-competition-darr.html
} 
Comparing approaches across the four surveyed communities, the most significant contrast appears to be between commercial instruments (crowdfunded products and commercial products aimed at disabled individuals) and academic papers. Most of the commercial instruments are MIDI controllers which, whatever their physical configuration, manage musical events on a note-by-note basis, or much more rarely, on a sequence-level basis. What might be seen as a limitation of MIDI - its lack of a signature built-in sound - is framed as an advantage of versatility ("play any sound you can imagine").

By contrast, the academic projects tend to give the performer higher-level control over precomposed or algorithmically generated material. The level of variety within each community (NIME, HCI, accessible instruments) appears to be at least as broad as any systematic difference between the communities, and there is substantial overlap in authorship between NIME and HCI communities.

These differences might be explained by the incentive structures in commercial versus academic work. Achieving commercial success requires reaching a broad audience, which may be more easily achieved with an instrument capable of generic note-level control, which makes relatively few assumptions about the kind of music the performer wants to play. By contrast, academic communities often value intellectual novelty. A new interactive paradigm, whether or not it is ultimately successful from the user's point of view, is more likely to be publishable than a new implementation of a well-established concept.

\subsection{Whose Artistry?}

No music technology can be aesthetically neutral. Every instrument imposes certain assumptions about the nature of the music it creates (Magnusson, 2009; Gurevich and Treviño, 2007), a topic further discussed in Chapter 8 of this book "Materialoriented musical interactions" (Mudd, 2019). The piano keyboard assumes that music should be composed of a set of discrete events with pitch material organised in semitones. The step sequencer assumes that music should be composed of repeating patterns, typically in multiples of 4 beats. Even in the ostensibly general-purpose MIDI instruments offered on Kickstarter, the demo videos offer hints of how the designers conceptualise their musical uses, with diatonic scales and use of layered loops common.

Still, many of the instruments introduced at NIME and the HCI conferences go a step further in explicitly incorporating particular musical styles or even particular pieces into the fundamental operation of the instrument. The result are instruments low in what Jordà (2004) would term macro-diversity (ability to play in different styles) and mid-diversity (ability to play different pieces), though perhaps still high in micro-diversity (ability to exhibit nuances within a piece). The results might be seen as an artistic collaboration between the instrument creator and the user(s).

The balance of artistry between designer and performer would appear to be at its most extreme in the popular Guitar Hero and Rock Band series of games, where 
both the audio and the sequence of buttons that must be pressed are fully precomposed. In a detailed study of these games, Miller (2009) finds that a third of players nonetheless say that the experience makes them creative, and that an online culture of performance virtuosity has emerged around the games despite the fixed audio tracks. Curiously, $74 \%$ of players in Miller's survey already play a musical instrument, with half playing guitar. This suggests that the game does not simply appeal as a way of enabling non-musicians to have the experience of making music, but may appeal to players for entirely different reasons.

\subsection{Target User Communities}

It is worth considering who are the target users of these instruments, and to what extent the design decisions are aligned with their skills and interests (a topic further discussed in Malloch and Wanderley (2017)). In the music and disability literature, the characteristics of the target population are often clear. For the rest, the claim that an instrument is for "everyone", frequently found in crowdfunding campaigns but also implicit in many academic papers, is encouragingly democratic but also vague from an evaluation point of view. Are the instruments primarily intended for users with musical knowledge (perhaps avid listeners) who possess no instrumental experience? Are they for music hobbyists or even experienced performers looking for something new? For complete novices with neither instrumental nor aural training?

For note-level MIDI controllers, the expectation that someone would use it to play their favourite music is predicated not only on having a command of the physical interface, but also on the experience and aural skills to put notes together into melodies and harmonies. While technical innovation could potentially make the physical actions easy to execute, musicianship also takes considerable practice, suggesting that these instruments may not be targeted at complete novices. Indeed, if the ease of producing pitched sound were the only requirement to enabling musicianship by novices, then the MIDI keyboard and the theremin would have long ago satisfied the needs of most prospective musicians.

Data on who backs a crowdfunding campaign is typically not publicly available, but it would be interesting to study whether the backers of the most popular Kickstarter instruments are new to making music or whether they are already skilled instrumentalists. Similarly, a study of the legacy of the academic instruments along the lines of Morreale and McPherson (2017), could reveal the extent to which these instruments succeeded in reaching a broad population.

\subsection{Virtuosity and Style}

For conductor systems and instruments featuring higher-level control of musical patterns, Blaine and Fels (2003) highlight the tradeoff whereby limited control can 
improve initial ease of use while reducing the upward path to virtuosity. Jordà (2004) also addresses this topic in his metric of instrument efficiency, defined as the ratio of musical output complexity to control input complexity. Whether any instrument has achieved the goal set out by Wessel and Wright (2002) of a "low entry fee with no ceiling on virtuosity", or whether this goal is even fully achievable, remains uncertain. Certainly some traditional instruments which have been marketed for their ease of use, such as the harmonica, have also been used virtuosically by skilled musicians.

A final set of questions concerns the nature of music itself. Many instruments for novices are promoted as allowing anyone to make music, but "music" is not one homogeneous entity but rather an umbrella term encompassing a huge variety of genres, styles and techniques. Few people would learn a traditional instrument to generically create music of any arbitrary style; most people are motivated to participate in particular genres, often ones they also listen to.

Yet style and genre receive comparatively little systematic attention in most papers and crowdfunding campaigns for new instruments. One might speculate that in many cases, digital instrument creators are people who have significant musical experience, perhaps being proficient at one or more traditional instruments. (A survey of the musical background of instrument builders would itself be an interesting study.) To what extent are these designers creating tools to make the kind of music they themselves are interested in?

In the case of interactive compositions, it seems evident that the designer is seeking to share their own aesthetic outlook with others (Schnell and Battier, 2002; Murray-Browne et al., 2011). But what of the simplified instruments and MIDI controllers which offer control on an individual note level? Particularly for those instruments that restrict "wrong" notes through imposing certain scales and temporal quantisation, the possible output might not be versatile enough to create music in most traditional or popular styles. In this case it is worth considering the designer's priorities. If the quality of the musical output is the primary goal, then would the designer themselves be interested to create or listen to music with the constraints they have set up? If not, is there an implicit assumption that non-musicians would be more likely than experienced performers to want to make this kind of music? Surveys and ethnographic studies could help elucidate the expectations of would-be musical performers.

On the other hand, many instruments may not be motivated by the characteristics of the musical output at all, but rather the in-the-moment experience of the person using it. Long-term engagement might or might not be a priority. This experienceoriented approach is often most explicit in the papers around therapeutic instruments and instruments for children, but it could equally well apply to anyone, just as games such as Guitar Hero can target the general population. There is surely no single correct approach to creating new digital instruments, but clarity in design goals and target population can be helpful for potential players and fellow designers alike. 


\section{Conclusion}

This paper has explored recent commercial and academic work on new musical instruments aimed at novices or non-musicians. The breadth of new designs over only 6 years' time shows how enticing a goal this remains for many instrument builders. We found a clear difference in approach between commercial instruments, where note-based MIDI controllers were prevalent, and academic projects, where interactive compositions and higher-level control metaphors were more common. By contrast, difference in design and evaluation strategies between NIME and HCI conferences were not self-evident, although instruments targeted for therapeutic use for individuals with disabilities followed their own set of priorities that did not entirely overlap with other instruments presented at NIME and HCI conferences.

Future study could focus on the legacy and evolution of such instruments. Crowdfunding is a venue for launching new ideas to the public. Can a similar variety of novel easy-to-play controllers be found on the shelves of established music shops, or are these projects inherently limited in duration of appeal? Do academic papers on these instruments show systematic development over time that suggests that authors are incorporating ideas from the previous literature? And for any given instrument, to what extent is it desired or expected that players would maintain a long-term engagement with it, in comparison to how long they might continue to play a traditional instrument?

The ability to perform music may best be viewed not as an engineering or societal problem to be solved, but as an open-ended creative opportunity where new ideas will always be welcome and even necessary. A reflective approach considering the breadth of previous work may in fact enhance the creativity of future designers in developing new musical outputs and creating engaging new experiences.

\section{References}

D. G. Arellano and A. McPherson. Radear: A tangible spinning music sequencer. In Proceedings of the International Conference on New Interfaces for Musical Expression, pages 84-85, London, United Kingdom, 2014. Goldsmiths, University of London.

J. Barbosa, J. Malloch, M. Wanderley, and S. Huot. What does 'evaluation' mean for the nime community? In E. Berdahl and J. Allison, editors, Proceedings of the International Conference on New Interfaces for Musical Expression, pages 156-161, Baton Rouge, Louisiana, USA, May 2015. Louisiana State University.

T. J. Barraclough, J. Murphy, and A. Kapur. New open-source interfaces for group based participatory performance of live electronic music. In Proceedings of the International Conference on New Interfaces for Musical Expression, pages 155158, London, United Kingdom, 2014. Goldsmiths, University of London.

D. Becking, C. Steinmeier, and P. Kroos. Drum-dance-music-machine: Construction of a technical toolset for low-threshold access to collaborative musical per- 
formance. In Proceedings of the International Conference on New Interfaces for Musical Expression, pages 112-117, Brisbane, Australia, 2016. Queensland Conservatorium Griffith University.

B. Bengler and N. Bryan-Kinns. Designing collaborative musical experiences for broad audiences. In Proceedings of the 9th ACM Conference on Creativity \& Cognition, pages 234-242. ACM, 2013.

E. Benjamin and J. Altosaar. Musicmapper: Interactive 2D representations of music samples for in-browser remixing and exploration. In E. Berdahl and J. Allison, editors, Proceedings of the International Conference on New Interfaces for Musical Expression, pages 325-326, Baton Rouge, Louisiana, USA, May 2015.

S. Bhat. Touchtone: An electronic musical instrument for children with hemiplegic cerebral palsy. In Proceedings of the Fourth International Conference on Tangible, Embedded, and Embodied Interaction, TEI '10, pages 305306, New York, NY, USA, 2010. ACM. ISBN 978-1-60558-841-4. doi: 10.1145/1709886.1709955. URL http://doi.acm.org/10.1145/1709886.1709955.

K. Bhumber, N. Lee, and B. Topp. Pendula: An interactive swing installation and performance environment. In Proceedings of the International Conference on New Interfaces for Musical Expression, pages 277-285, Brisbane, Australia, 2016.

T. Blaine and S. Fels. Collaborative musical experiences for novices. Journal of New Music Research, 32(4):411-428, 2003.

J. Buschert. Musician maker: Play expressive music without practice. In NIME, 2012.

B. Cappelen and A. Andersson. Designing four generations of 'Musicking Tangibles'. Music, Health, Technology and Design, 8:1-19, 2014.

E. Chew and A. McPherson. Performing music: humans, computers and electronics. In R. Ashley and R. Timmers, editors, The Routledge Companion to Music Cognition. NY: Taylor and Francis, 2017.

G. Chuang, S. Wang, S. Burns, and O. Shaer. Emotisphere: From emotion to music. In Proceedings of the Ninth International Conference on Tangible, Embedded, and Embodied Interaction, pages 599-602. ACM, 2015.

L. Dahl and S. Robaszkiewicz. For novices playing music together, adding structural constraints leads to better music and may improve user experience. In Adjunct proceedings of the 25th annual ACM symposium on User interface software and technology, pages 85-86. ACM, 2012.

H. Diao, Y. Zhou, C. A. Harte, and N. Bryan-Kinns. Sketch-based musical composition and performance. In Proceedings of the International Conference on New Interfaces for Musical Expression, pages 569-572, London, United Kingdom, 2014. Goldsmiths, University of London.

S. Favilla and S. Pedell. Touch Screen Collaborative Music: Designing NIME for Older People with Dementia. Proceedings of the International Conference on New Interfaces for Musical Expression, pages 35-39, 2014. doi: $10.1145 / 2541016.2541088$. 
S. Ferguson and M. M. Wanderley. The mcgill digital orchestra: An interdisciplinary project on digital musical instruments. Journal of Interdisciplinary Music Studies, 4(2): 17-35, 2010.

R. Fiebrink. Real-time interaction with supervised learning. In Proc. CHI Extended Abstracts, 2010.

C. Frisson, S. Dupont, J. Leroy, A. Moinet, T. Ravet, X. Siebert, and T. Dutoit. Loopjam: turning the dance floor into a collaborative instrumental map. In NIME, 2012.

S. Glickman, B. Lee, F. Y. Hsiao, and S. Das. Music everywhere - augmented reality piano improvisation learning system. In Proceedings of the International Conference on New Interfaces for Musical Expression, pages 511-512, Copenhagen, Denmark, 2017. Aalborg University Copenhagen.

K. Graham-Knight and G. Tzanetakis. Adaptive Music Technology - History and Future Perspectives. International Computer Music Conference Proceedings, pages 416-419, 2015. doi: 10.1145/2769493.2769583.

M. Grierson and C. Kiefer. NoiseBear: a wireless malleable multiparametric controller for use in assistive technology contexts. CHI '13 Extended Abstracts on Human Factors in Computing Systems, pages 2923-2926, 2013a. doi: $10.1145 / 2468356.2479575$.

M. Grierson and C. Kiefer. NoiseBear: A Malleable Wireless Controller Designed In Participation with Disabled Children. Proceedings of the International Conference on New Interfaces for Musical Expression, pages 413-416, $2013 \mathrm{~b}$.

G. Griffin and R. Jacob. Priming creativity through improvisation on an adaptive musical instrument. In Proceedings of the 9th ACM Conference on Creativity \& Cognition, pages 146-155. ACM, 2013.

M. Gurevich and J. Treviño. Expression and its discontents: toward an ecology of musical creation. In Proceedings of the 7th international conference on New interfaces for musical expression, pages 106-111, 2007.

A.-M. S. Hansen, H. J. Andersen, and P. Raudaskoski. Two shared rapid turn taking sound interfaces for novices. In NIME, 2012.

J. Harriman. Start 'em young: Digital music instrument for education. In E. Berdahl and J. Allison, editors, Proceedings of the International Conference on New Interfaces for Musical Expression, pages 70-73, Baton Rouge, Louisiana, USA, May 2015. Louisiana State University.

F. Heller, I. M. C. Ruiz, and J. Borchers. An augmented flute for beginners. In Proceedings of the International Conference on New Interfaces for Musical Expression, pages 34-37, Copenhagen, Denmark, 2017. Aalborg University Copenhagen.

S. Holland and R. Fiebrink. Machine learning, music and creativity: An interview with Rebecca Fiebrink. In S. Holland, T. Mudd, K. Wilkie-McKenna, A. McPherson, and M. Wanderley, editors, New Directions in Music and Human-Computer Interaction. Springer, London, 2019.

A. Hunt, R. Kirk, and M. Neighbour. Interfaces for Music Therapy. IEEE Multimedia, 2004. 
Jackie, Y. T. Chui, M. Marafa, Samson, and K. F. Young. Solotouch: A capacitive touch controller with lick-based note selector. In Proceedings of the International Conference on New Interfaces for Musical Expression, pages 389-393, Daejeon, Republic of Korea, May 2013. Graduate School of Culture Technology, KAIST.

K. B. Jakobsen, M. G. Petersen, M. K. Rasmussen, J. E. Groenbaek, J. Winge, and J. Stougaard. Hitmachine: Collective musical expressivity for novices. In Proceedings of the International Conference on New Interfaces for Musical Expression, pages 241-246, Brisbane, Australia, 2016.

A. Jense and H. Leeuw. WamBam : A case study in design for an electronic musical instrument for severely intellectually disabled users. Proceedings of the International Conference on New Interfaces for Musical Expression, pages 74-77, 2015.

A. R. Jensenius and A. Voldsund. The music ball project: Concept, design, development, performance. 2012.

S. Jordà. Instruments and players: Some thoughts on digital lutherie. Journal of New Music Research, 33(3):321-341, 2004.

S. Kaneko. A function-oriented interface for music education and musical expressions: "the sound wheel". In Proceedings of the International Conference on New Interfaces for Musical Expression, pages 202-205, Daejeon, Republic of Korea, May 2013. Graduate School of Culture Technology, KAIST.

S. Katan, M. Grierson, and R. Fiebrink. Using Interactive Machine Learning to Support Interface Development Through Workshops with Disabled People. CHI 2015, 2015.

C. Kiefer, N. Collins, and G. Fitzpatrick. HCI methodology for evaluating musical controllers: A case study. In Proc. NIME, pages 87-90, 2008.

T. Kitahara, S. Giraldo, and R. Ramrez. Jamsketch: A drawing-based real-time evolutionary improvisation support system. In Proceedings of the International Conference on New Interfaces for Musical Expression, pages 505-506, Copenhagen, Denmark, 2017. Aalborg University Copenhagen.

K. Klipfel. Midi motion: Interactive music composition gloves. In Proceedings of the Tenth International Conference on Tangible, Embedded, and Embodied Interaction, pages 757-760. ACM, 2017.

B. Knichel, H. Reckter, and P. Kiefer. resonate - a social musical installation which integrates tangible multiuser interaction. In E. Berdahl and J. Allison, editors, Proceedings of the International Conference on New Interfaces for Musical Expression, pages 111-115, Baton Rouge, Louisiana, USA, May 2015. Louisiana State University.

S. Kountouras and I. Zannos. Gestus: Teaching soundscape composition and performance with a tangible interface. In Proceedings of the International Conference on New Interfaces for Musical Expression, pages 336-341, Copenhagen, Denmark, 2017. Aalborg University Copenhagen.

J. V. Larsen, D. Overholt, and T. B. Moeslund. The actuated guitar: Implementation and user test on children with hemiplegia. In NIME '14 Proceedings of the 2014 Conference on New Interfaces for Musical Expression, pages 60-65, 2014. URL http://www.nime.org/proceedings/2014/nime2014_486.pdf. 
J. V. Larsen, D. Overholt, and T. B. Moeslund. The Prospects of Musical Instruments For People with Physical Disabilities. NIME '16 Proceedings of the 2016 Conference on New Interfaces for Musical Expression, pages 327-331, 2016.

M. Luhtala, T. Kymäläinen, and J. Plomp. Designing a Music Performance Space for Persons with Intellectual Learning Disabilities. Proceedings of the International Conference on New Interfaces for Musical Expression, (June):429-432, 2011. ISSN 2220-4806.

S. Lui. Generate expressive music from picture with a handmade multi-touch music table. In E. Berdahl and J. Allison, editors, Proceedings of the International Conference on New Interfaces for Musical Expression, pages 374-377, Baton Rouge, Louisiana, USA, May 2015. Louisiana State University.

F. Lyu, F. Tian, W. Feng, X. Cao, X. L. Zhang, G. Dai, and H. Wang. Ensewing: Creating an instrumental ensemble playing experience for children with limited music training. In Proceedings of the 2017 CHI Conference on Human Factors in Computing Systems, pages 4326-4330. ACM, 2017.

T. Magnusson. Of epistemic tools: Musical instruments as cognitive extensions. Organised Sound, 14(02):168-176, 2009.

J. Malloch and M. Wanderley. Embodied cognition and digital musical instruments: Design and performance. In M. Lesaffre, P.-J. Maes, and M. Leman, editors, The Routledge Companion to Embodied Music Interaction, pages 440-449. Routledge, 2017.

M. V. Mathews. The radio baton and conductor program, or: Pitch, the most important and least expressive part of music. Computer Music Journal, 15(4):37-46, 1991.

D. Meckin and N. Bryan-kinns. moosikMasheens: Music, motion and narrative with young people who have complex needs. Idc 2013, pages 66-73, 2013. ISSN 9781450319188. doi: 10.1145/2485760.2485776.

E. M. Miletto, M. S. Pimenta, F. Bouchet, J.-P. Sansonnet, and D. Keller. Principles for music creation by novices in networked music environments. Journal of New Music Research, 40(3):205-216, 2011.

K. Miller. Schizophonic performance: Guitar hero, rock band, and virtual virtuosity. Journal of the Society for American Music, 3(4):395-429, 2009.

F. Morreale and A. De Angeli. Evaluating visitor experiences with interactive art. In Proceedings of the 11th Biannual Conference on Italian SIGCHI Chapter, pages 50-57. ACM, 2015.

F. Morreale and A. McPherson. Design for longevity: Ongoing use of instruments from NIME 2010-14. In Proceedings of the International Conference on New Interfaces for Musical Expression, pages 192-197, Copenhagen, Denmark, 2017. Aalborg University Copenhagen.

F. Morreale, R. Masu, A. De Angeli, and P. Rota. The music room. In CHI'13 Extended Abstracts on Human Factors in Computing Systems, pages 3099-3102. ACM, 2013.

T. Mudd. Material-oriented musical interactions. In S. Holland, T. Mudd, K. WilkieMcKenna, A. McPherson, and M. Wanderley, editors, New Directions in Music and Human-Computer Interaction. Springer, London, 2019. 
T. Murray-Browne, D. Mainstone, N. Bryan-Kinns, and M. D. Plumbley. The medium is the message: Composing instruments and performing mappings. In Proceedings of the International Conference on New Interfaces for Musical Expression, pages 56-59, 2011.

Y. Nakanishi, S. Matsumura, and C. Arakawa. B.O.M.B. -Beat Of Magic Box -: Stand-alone synthesizer using wireless synchronization system for musical session and performance. In Proceedings of the International Conference on New Interfaces for Musical Expression, pages 80-81, London, United Kingdom, 2014. Goldsmiths, University of London.

S. Nam. Musical poi (mPoi). In Proceedings of the International Conference on New Interfaces for Musical Expression, pages 148-151, Daejeon, Republic of Korea, May 2013. Graduate School of Culture Technology, KAIST.

A. Nath and S. Young. VESBALL : A ball-shaped instrument for music therapy. Proceedings of the International Conference on New Interfaces for Musical Expression, pages 387-391, 2015.

J. A. Paradiso. The brain opera technology: New instruments and gestural sensors for musical interaction and performance. Journal of New Music Research, 28(2): 130-149, 1999.

C. Poepel, J. Feitsch, M. Strobel, and C. Geiger. Design and evaluation of a gesture controlled singing voice installation. In Proceedings of the International Conference on New Interfaces for Musical Expression, pages 359-362, London, United Kingdom, 2014. Goldsmiths, University of London.

J. qi Deng, F. C. M. Lau, H.-C. Ng, Y.-K. Kwok, H.-K. Chen, and Y. heng Liu. Wijam: A mobile collaborative improvisation platform under master-players paradigm. In Proceedings of the International Conference on New Interfaces for Musical Expression, pages 407-410, London, United Kingdom, 2014. Goldsmiths, University of London.

D. Robson. Play!: Sound toys for the non musical. In Proceedings of the 2001 conference on New interfaces for musical expression, 2001.

N. Schnell and M. Battier. Introducing composed instruments, technical and musicological implications. In Proceedings of the 2002 conference on New interfaces for musical expression, pages 1-5, 2002.

N. Schnell, S. Robaszkiewicz, F. Bevilacqua, and D. Schwarz. Collective sound checks: Exploring intertwined sonic and social affordances of mobile web applications. In Proceedings of the Ninth International Conference on Tangible, Embedded, and Embodied Interaction, pages 685-690. ACM, 2015.

E. Shahar. Soundstrand: Composing with a tangible interface. In NIME, 2012.

R. B. Shapiro, R. Fiebrink, M. Ahrens, and A. Kelly. BlockyTalky: A physical and distributed computer music toolkit for kids. In Proceedings of the International Conference on New Interfaces for Musical Expression, volume 16 of 2220-4806, pages 427-432, Brisbane, Australia, 2016. Queensland Conservatorium Griffith University. ISBN 978-1-925455-13-7.

C. Tam, H. Schwellnus, C. Eaton, Y. Hamdani, A. Lamont, and T. Chau. Movementto-music computer technology: A developmental play experience for children 
with severe physical disabilities. Occupational Therapy International, 14(2):99112, 2007. ISSN 09667903. doi: 10.1002/oti.227.

A. Tanaka, B. Caramiaux, and N. Schnell. MubuFunkScatShare: gestural energy and shared interactive music. In CHI'13 Extended Abstracts on Human Factors in Computing Systems, pages 2999-3002. ACM, 2013.

C. Trappe. Making sound synthesis accessible for children. In NIME, 2012.

S. Trento and S. Serafin. Flag beat: a novel interface for rhythmic musical expression for kids. In Proceedings of the International Conference on New Interfaces for Musical Expression, pages 456-459, Daejeon, Republic of Korea, May 2013. Graduate School of Culture Technology, KAIST.

J. Tresch and E. I. Dolan. Toward a new organology: Instruments of music and science. OSIRIS, 28:278-298, 2013.

A. van Troyer. MM-RT: A tabletop musical instrument for musical wonderers. In Proceedings of the International Conference on New Interfaces for Musical Expression, pages 186-191, Copenhagen, Denmark, 2017. Aalborg University Copenhagen.

M. M. Wanderley and P. Depalle. Gestural control of sound synthesis. Proceedings of the IEEE, 92(4):632-644, 2004.

M. M. Wanderley and N. Orio. Evaluation of input devices for musical expression: Borrowing tools from HCI. Computer Music Journal, 26(3):62-76, 2002.

G. Wang. Game design for expressive mobile music. In Proceedings of the International Conference on New Interfaces for Musical Expression, volume 16 of 2220-4806, pages 182-187, Brisbane, Australia, 2016. Queensland Conservatorium Griffith University. ISBN 978-1-925455-13-7.

A. Ward, L. Woodbury, and T. Davis. Design Considerations for Instruments for Users with Complex Needs in SEN Settings. In Nime '17, pages 216-221, 2017.

D. Wessel and M. Wright. Problems and prospects for intimate musical control of computers. Computer Music Journal, 26(3):11-22, 2002.

F. Zamorano. Simpletones: A system of collaborative physical controllers for novices. In NIME, 2012.

F. Zamorano. SimpleTones: a collaborative sound controller system for nonmusicians. In CHI'13 Extended Abstracts on Human Factors in Computing Systems, pages 3155-3158. ACM, 2013. 